\title{
Identificación de asociaciones clínico-patológicas e hipermetilación de genes supresores de tumores en cáncer gástrico difuso a través de análisis de Hierarchical clustering
}

\author{
Luis Zavala $\mathrm{G}^{1 \mathrm{a}}$, Víctor Luengo J $\mathrm{J}^{1 \mathrm{a}}$, Francisco 0 ssandón $\mathrm{C}^{1 \mathrm{~b}}$, \\ Erick Riquelme $\mathbf{S}^{1 \mathrm{c}}$, Claudia Backhouse $\mathrm{E}^{2 \mathrm{C}}$, Mariana Palma $\mathbf{V}^{2 \mathrm{c}}$, \\ Jorge Argandoña C'2d, Miguel Angel Cumsille 3 , \\ Alejandro Corvalán $\mathbf{R}^{\mathbf{1 , 2}}$. \\ Hierarchical clustering analysis to detect \\ associations between clinical and \\ pathological features of gastric tumors \\ and hypermethylation of suppressor genes
}

Background: Methylation is an inactivation mechanism for tumor suppressor genes, that can have important clinical implications. Aim: To analyze the methylation status of 11 tumor suppressor genes in pathological samples of diffuse gastric cancer. Material and methods: Eighty three patients with diffuse gastric cancer with information about survival and infection with Epstein Barr virus, were studied. DNA was extracted from pathological slides and the methylation status of genes p14, p15, p16, APC, p73, FHIT, E-caderin, SEMA3B, BRCA-1, MINT-2 y MGMT, was studied using sodium bisulphite modification and polymerase chain reaction. Results were grouped according to the methylation index or Hierarchical clustering (TIGR MultiExperiment Viewer). Results: Three genes had a high frequency of methylation (FHIT, BRCA1, APC), four had an intermediate frequency (p15, MGMT, p14, MINT) and four had a low frequency (p16, p73, Ecadherin, SEMA3B). The methylation index had no association with clinical or pathological features of tumors or patients survival. Hierarchical clustering generated two clusters. One grouped clinical and pathological features with FHIT, BRCA1, and APC and the other grouped the other eight genes and Epstein Barr virus infection. Two significant associations were found, between APC and survival and p16/p14 and Epstein Barr virus infection. Conclusions: Hierarchical clustering is a tool that identifies associations between clinical and pathological features of tumors and methylation of tumor suppressor genes (Rev Méd Chile 2006; 134: 17-25).

(Key words: Cluster analysis; Genes, supressor; Stomach neoplasms)

Recibido el 9 de enero, 2006. Aceptado el 29 de mayo, 2006.

Proyecto financiado por FONDECYT 1030130.

${ }_{1}^{1}$ Departamento de Anatomía Patológica, Facultad de Medicina Pontificia Universidad Católica de Chile, ${ }^{2}$ Instituto Chileno Japonés de Enfermedades Digestivas, Hospital Clínico-San Borja Arriarán, Campus Centro y ${ }^{3}$ Escuela de Salud Pública, Facultad de Medicina Universidad de Chile.

aAlumno de Medicina

bAlumno de Bioquímica

cTecnólogo Médico

dLicenciado en Tecnología Médica

eMagíster en Bioestadística

Correspondencia a: Dr. Alejandro Corvalán. Departamento de Anatomía Patológica, Facultad de Medicina, Pontificia Universidad Católica de Chile. Lira $854^{\circ}$ piso, Santiago. Tel: (2) 3543209. Fax: 6395101. E mail: corvalan@med.puc.cl 
$\mathrm{E}^{1}$ cáncer gástrico representa la segunda causa de muerte por cáncer en el mundo ${ }^{1}$. En Latinoamérica, Chile ocupa el segundo lugar en mortalidad después de Costa Rica, sumando ambos países casi $50 \%$ de la mortalidad en este continente $^{2}$. En Chile, el cáncer gástrico es la primera causa de muerte por enfermedades neoplásicas ${ }^{3}$, a pesar de una constante declinación en su mortalidad durante varias décadas y una estabilización entre 19 y 20 por 100.000 habitantes a fines de la década 1990-994. En este mismo período ha ocurrido un cambio en el perfil epidemiológico del cáncer gástrico, ya que se ha reportado un aumento en la proporción de casos de cáncer gástrico difuso (CGD), una característica considerada de mal pronóstico para esta enferme$\operatorname{dad}^{9}$.

Desde mediados de la década 1980-89, el reconocimiento de activación de oncogenes e inactivación de genes supresores de tumores (GST) en el proceso neoplásico, ha permitido proponer un modelo genético del cáncer, en el que por lo general existe un tipo de genes (GST u oncogenes) asociado de forma específica a un tipo de cáncer. Así, la identificación de los GST responsables del CGD tendría un impacto importante en el diagnóstico precoz, ya que podrían utilizarse como marcadores de tamizaje en sujetos con riesgo de desarrollar esta enfermedad. Los GST pueden ser inactivados por 2 mecanismos, deleción y metilación. Entre ellos, la metilación ocurre por incorporación de un grupo metilo en el carbono 5 de citosina, convirtiéndola en 5-metilcitosina ${ }^{10}$. Esta modificación epigenética ocurre con mayor frecuencia en regiones regulatorias de la expresión génica (secuencias promotoras), provocando represión transcripcional y, en consecuencia, inactivación génica ${ }^{10,11}$. La metilación ha sido recientemente reconocida como mecanismo frecuente de inactivación de GST en tumores humanos y algunos de ellos con importantes asociaciones clínico-patológicas ${ }^{12-22}$. Sin embargo, el estudio de la inactivación de GST por metilación y su significado clínico-patológico en CGD es escasa y de genes aislados ${ }^{23}$.

Actualmente, el reconocimiento del significado clínico-patológico de marcadores requiere de nuevas herramientas estadísticas. En este sentido el análisis mediante hierarchical clustering, una heramienta de emergente uso, ya que permite agrupar información recogida de múltiples variables y asociarlas a casos con características similares entre sí, generando clusters o agrupamientos. A partir de los clusters generados sería posible identificar asociaciones entre marcadores biológicos (como metilación de ciertos genes) y variables clínico-patológicas particulares. El objetivo de este trabajo es analizar la frecuencia de metilación de la región promotora de 11 GST relacionados a distintas vías metabólicas relevantes en la patogénesis del CGD y explorar sus asociaciones con variables clínico-patológicas utilizando el método de hierarchical clustering.

\section{MATERIALES Y MÉTODOS}

Casos clínicos. El estudio se realizó a partir de 305 casos de cáncer gástrico, en tejido incluido en parafina, de piezas quirúrgicas de pacientes operados entre 1993 y 1999 en el Instituto ChilenoJaponés de Enfermedades Digestivas - Hospital Clínico San Borja Arriarán. De este material, y utilizando la definición de Lauren ${ }^{24}$ para CGD ${ }^{25}$, se identificaron 83 casos que son la base del presente estudio. Las características clínicas de estos casos se obtuvieron de la revisión de fichas médicas y las características patológicas de informes anátomo-patológicos y revisión de láminas correspondientes. Las características clínicas consideradas fueron sexo (hombre, mujer), edad (menor o igual a 58 años, mayor de 58 años), sobrevida global (censura). Las características anátomo-patológicas consideradas fueron ubicación del tumor (antral, no antral), infiltración de pared gástrica (mucosa/submucosa, muscular propia/serosa) y compromiso ganglionar (sin consignar número de ganglios comprometidos) de acuerdo a la Unión Internacional Contra el Cáncer. Adicionalmente, incluimos la presencia del virus Epstein Barr (EBV) como variable anátomo-patológica en este estudio, dado que nuestro grupo ha descrito recientemente una fuerte asociación entre CGD y la infección por EBV ${ }^{26}$. Este estudio cuenta con la aprobación del Comité de Ética del Servicio de Salud Metropolitano Central (Hospital Clínico San Borja Arriarán).

Extracción de ADN. A partir de cortes histológicos de 50 micras, se realizó extracción de ADN según 
el método de proteinasa $\mathrm{K}^{27}$. Brevemente, el tejido obtenido del corte histológico fue traspasado a tubos de $1,5 \mathrm{ml}$ y resuspendido en $100 \mu \mathrm{L}$ de tampón de extracción (Tris pH 8,0, 50 mM; EDTA $1 \mathrm{mM}$; Tween 20 0,5\%) con proteinasa K (1 mg/ $\mathrm{ml})$. Las muestras fueron incubadas a $55^{\circ} \mathrm{C} \times 12 \mathrm{~h}$ y a $100^{\circ} \mathrm{C}$ x $10 \mathrm{~min}$; luego, centrifugadas a 12.000 r.p.m. por 20 min y el sobrenadante traspasado a tubos estériles y mantenidos a $-30^{\circ} \mathrm{C}$ hasta su modificación por bisulfito de sodio.

Modificación por bisulfito de sodio. El método se basa en la conversión de todos los residuos de citosinas no metiladas a uracilos (U) mediante deaminación. Sin embargo, los residuos metilados de citosinas que son resistentes a la modificación permanecen como citosinas ${ }^{28,29}$. Esta diferencia es utilizada en la amplificación por PCR a través de partidores específicos para cada condición. Brevemente, a $25 \mu \mathrm{L}$ de ADN extraído, se agregaron $25 \mu \mathrm{L}$ de agua bidestilada estéril, $5,5 \mu \mathrm{L}$ de $\mathrm{NaOH} 2 \mathrm{M}$ y se incubó a $37^{\circ} \mathrm{C}$ durante $10 \mathrm{~min}$. Luego agregamos $30 \mu \mathrm{L}$ de hidroquinona $(55 \mathrm{mg}$ en $50 \mathrm{ml}$ de agua estéril) y $520 \mu \mathrm{L}$ de bisulfito de sodio $(3,76 \mathrm{~g}$ en $10 \mathrm{~mL}$ de agua estéril) y se incubó a $55^{\circ} \mathrm{C}$ durante $16 \mathrm{~h}$, de acuerdo a protocolos publicados para tejido incluido en parafina. Posteriormente, se utilizó el sistema de purificación Wizard ${ }^{\circledR}$ (Promega), agregando $1 \mathrm{~mL}$ de resina de purificación a $500 \mu \mathrm{L}$ de ADN tratado con bisulfito de sodio. Luego, lavamos con $2 \mathrm{~mL}$ de isopropanol, adicionamos $50 \mu \mathrm{L}$ de agua bidestilada a $65^{\circ} \mathrm{C}$ y $8,25 \mu \mathrm{L}$ de $\mathrm{NaOH} 2 \mathrm{M}, 1 \mu \mathrm{L}$ de glicógeno ultrapuro y $17 \mu \mathrm{L}$ de acetato de amonio $10 \mathrm{M}$. La mezcla fue precipitada en etanol absoluto a $-20^{\circ} \mathrm{C}$ durante $1 \mathrm{~h}$, resuspendida en $50 \mu \mathrm{L}$ de agua DEPC.

Reacción de polimerasa en cadena. La reacción de polimerasa en cadena se realizó en un volumen de $25 \mu \mathrm{L}$ con $10 \mathrm{mM}$ Tris- $\mathrm{HCl} \mathrm{pH}$ 8.0, $50 \mathrm{mM} \mathrm{KCl}$, $1.5 \mathrm{mM} \mathrm{MgCl}, 200 \mu \mathrm{M}$ dNTP, $0.5 \mu \mathrm{M}$ partidores, 2.5 $\mathrm{U}$ Taq polimerasa y $4 \mu \mathrm{L}$ de ADN extraído y tratado con bisulfito previamente. Las condiciones de amplificación fueron desnaturación inicial a $94^{\circ} \mathrm{C} \times 5 \min \times 1 \mathrm{vez}$, seguidos de 40 ciclos de desnaturación a $94^{\circ} \mathrm{C}$ x $30 \mathrm{~s}$, alineamiento a $63^{\circ} \mathrm{C}$ x 1 min y extensión a $72^{\circ} \mathrm{C}$ x $30 \mathrm{~s}$; posteriormente sigue una extensión final de $72^{\circ} \mathrm{C}$ x $5 \mathrm{~min}$. La temperatura de alineamiento se ajustó experimen- talmente para cada gen incluido en el estudio. Para cada muestra se realizó en paralelo la amplificación del gen ß-globina humana, para controlar pérdida de señal y eficiencia de la reducción. El resultado se analizó por electroforesis en geles de agarosa al 3\% a 200 volts, durante 20 min y visualización por luz UV posterior a tinción con bromuro de etidio al 0,05\%. Los genes seleccionados en este análisis fueron p14, p15, p16, APC, p73, FHIT, E-caderina, SEMA3B, BRCA1, MINT2 y $\mathrm{MGMT}^{30}$, en base a revisión de la literatura. Dado el alto número de genes y casos analizados, utilizamos la estrategia descrita por Kang y $\mathrm{Col}^{27}$ en la cual se amplifica la condición metilada de todos los genes analizados, pero sólo la condición no metilada del gen p16, como control positivo de modificación de bisulfito de sodio. Las secuencias de los partidores y el tamaño de amplificación fueron tomados de la literatura y se muestran en la Tabla 1.

Estadística. Los resultados fueron agrupados según el índice de metilación (IM), que se define como la proporción de genes con metilación positiva dentro del total de genes analizados y se clasificó como alto si tenía un valor mayor a 30\% o bajo si era menor a 30\%, de acuerdo a Makarla et $\mathrm{al}^{31}$. Adicionalmente utilizamos el método hierarchical clustering, el cual mide la similitud de las variables analizadas mediante la métrica euclidiana, considerando la máxima distancia de los componentes de los clusters entre sí (complete linkage) ${ }^{32}$. De este modo el hierarchical clustering, a diferencia de otros métodos estadísticos, permite tener una visión gráfica de asociaciones particulares entre los genes estudiados y las variables clínico-patológicas entre sí y no promedios de datos como el IM. Las asociaciones más cercanas observadas mediante el hierarchical clustering fueron confirmadas por el test de chi cuadrado, con un valor significativo de $\mathrm{p}<0,05$ (Epinfo 2000).

\section{RESULTADOS}

Los casos seleccionados correspondieron a 53 hombres y 30 mujeres, con un promedio de edad de 57,8 (rango 20-84) años. Cuarenta y ocho casos $(60,8 \%)$ estaban en localización no antral y 31 
Tabla 1. Secuencias de partidores y condiciones de PCR para M S-PC R

\begin{tabular}{|c|c|c|c|}
\hline Gen & Partidores (forward/reverse)(5'-3') & tamaño & $\mathrm{T}\left({ }^{\circ} \mathrm{C}\right)$ \\
\hline \multirow[t]{2}{*}{ FHIT-M } & TTGGGGCGCGGGTTTGGGTTTTTACGC & & \\
\hline & CGTAAACGACGCCGACCCCACTA & 74 & TD71-64 \\
\hline \multirow[t]{2}{*}{ BRCA1-M } & TCGTGGTAACGGAAAAGCGC & & \\
\hline & AAATCTCAACGAACTCACGCCG & 75 & TD61-58 \\
\hline \multirow[t]{2}{*}{ APC-M } & TATTGCGGAGTGCGGGTC & & \\
\hline & TCGACGAACTCCCGACGA & 98 & 55 \\
\hline \multirow[t]{2}{*}{ P15-M } & GGTTTTTTATTTTGTTAGAGCGAGGC & & \\
\hline & TAACCGCAAAATACGAACGCG & 68 & TD61-58 \\
\hline \multirow[t]{2}{*}{ MGMT-M } & TTTCGACGTTCGTAGGTTTTCGC & & \\
\hline & GCACTCTTCCGAAAACGAAACG & 81 & 59 \\
\hline \multirow[t]{2}{*}{ P14-M } & GTGTTAAAGGGCGGCGTAGC & & \\
\hline & AAAACCCTCACTCGCGACGA & 122 & 60 \\
\hline \multirow[t]{2}{*}{ MINT2-M } & AATCGAATTTGTCGTCGTTTC & & \\
\hline & AAATAAATAAATAAAAAAAAACGCG & 88 & 60 \\
\hline \multirow[t]{2}{*}{ P73-M } & GGACGTAGCGAAATCGGGGTTC & & \\
\hline & ACCCCGAACATCGACGTCCG & 60 & TD61-58 \\
\hline \multirow[t]{2}{*}{ E-Caderina-M } & TGTAGTTACGTATTTATTTTTAGTGGCGTC & & \\
\hline & CGAATACGATCGAATCGAACCG & 112 & TD61-58 \\
\hline \multirow[t]{2}{*}{ SEMA3B-M } & TGGTTAGGCGGGGTATTTTC & & \\
\hline & TCAACAATAAAAACGAAAACG & 133 & 55 \\
\hline \multirow[t]{2}{*}{ P16-M } & TTATTAGAGGGTGGGGCGGATCGC & & \\
\hline & GACCCCGAACCGCGACCGTAA & 150 & 65 \\
\hline \multirow[t]{2}{*}{ P16-UM } & TTATTAGAGGGTGGGGTGGATTGT & & \\
\hline & СААССССАААССАСААССАТАА & 151 & 60 \\
\hline
\end{tabular}

$\mathrm{M}=$ metilado. $\mathrm{UM}=$ no metilado.

$(39,2 \%)$ en ubicación antral. En 4 casos (5\%), la localización no estaba consignada. Doce $(14,5 \%)$ tumores eran incipientes (1 con metástasis ganglionar) y $70(84,3 \%)$ avanzados. En un caso $(1,2 \%)$ el estadio no fue consignado. Veintiún tumores $(25,3 \%)$ de la serie eran de tipo mucinoso (10 casos) y anillo de sello (11 casos). Al momento de la selección, 46 pacientes estaban muertos (42 de ellos por CGD y 4 por otras causas), con un promedio de sobrevida de 68,2 meses.

Frecuencia de metilación genética en 83 casos de cáncer gástrico difuso (CGD). La frecuencia de metilación de 11 GST en 83 casos consecutivos de CGD se muestra en la Tabla 2 y Figura 1. La frecuencia de metilación varió desde 67,5\% (FHIT)
Tabla 2. H ipermetilación en 83 casos de cáncer gástrico difuso

\begin{tabular}{|llc|}
\hline Gen & N & $\%$ \\
\hline FHIT & 56 & 67,5 \\
BRCA1 & 46 & 55,4 \\
APC & 39 & 47,0 \\
P15 & 25 & 30,1 \\
MGMT & 22 & 26,5 \\
P14 & 20 & 24,1 \\
MNT2 & 18 & 21,7 \\
P16 & 16 & 19,3 \\
P73 & 16 & 19,3 \\
E-Caderina & 14 & 16,9 \\
SEMA3B & 13 & 15,7 \\
\hline
\end{tabular}




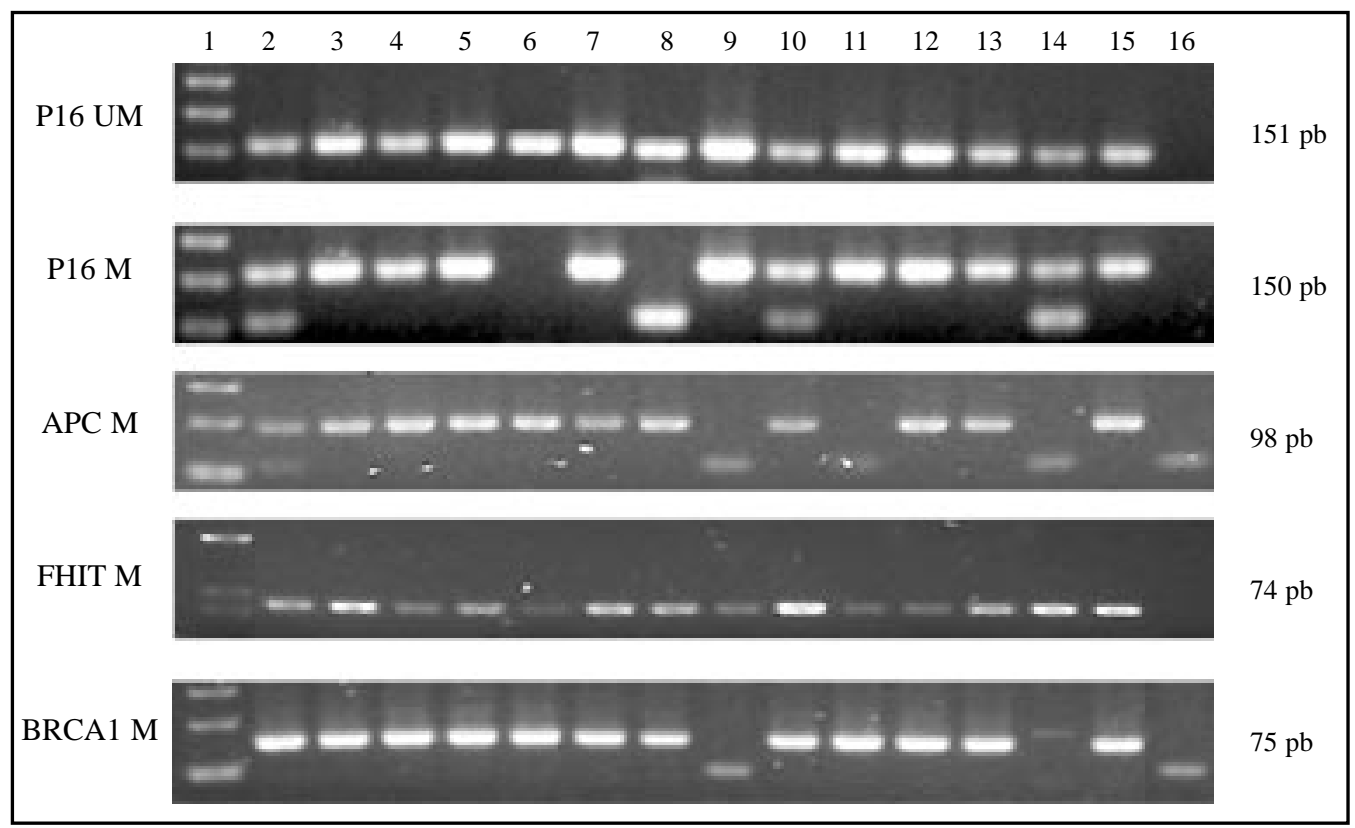

Figura 1. Ejemplos representativos de PCR metilación específica (MS-PCR) para la forma no metilada de p16 (NM) y metiladas de p16, BRCA1 y APC.

a $15,7 \%$ (SEMA3B). Tres genes demostraron una alta frecuencia de metilación: FHIT, BRCA1 y APC, 4 genes demostraron una frecuencia intermedia: p15, MGMT, p14 y MNT2 y 4 genes demostraron una frecuencia baja de metilación: p16, p73, Ecaderina y SEMA3B. No se observan casos sin metilación en los genes estudiados.

Índice de metilación y correlaciones clínico-patológicas. Para comprender el significado clínico-patológico de la metilación de 11 genes en 83 casos consecutivos de CGD, agrupamos nuestros resultados de acuerdo al IM (ver Materiales y métodos). Treinta seis casos tuvieron un IM mayor a 30\% y se consideraron como IM alto. Cuarenta y siete casos tuvieron un IM menor a 30\% y fueron considerados IM bajo. Las correlaciones clínico-patológicas de ambos grupos se muestran en la Tabla 3. No encontramos características clínico-patológicas específicas de uno u otro grupo, con la excepción de una tendencia a baja frecuencia de infección por virus de Epstein-Barr en los casos IM bajo ( $p$ $=0,07)$. El análisis de sobrevida mediante el método de Kaplan-Meier, no demostró asociaciones entre sobrevida e IM (datos no mostrados).
Análisis de hierarchical clustering y correlaciones clínico-patológicas. Para identificar asociaciones de metilación de genes particulares con variables clínico-patológicas específicas realizamos el análisis de hierarchical clustering (Figura 2). Este análisis nos generó dos clusters uno superior, donde se agruparon todas las variables clínico-patológicas (excepto ubicación y presencia de EBV) y los tres genes de mayor frecuencia de metilación identificados en este estudio (FHIT, BRCA1 y APC). Por otra parte, en el cluster inferior, se agruparon los restantes 8 genes junto con la variable ubicación e infección por EBV. A partir de los clusters generados, realizamos análisis de asociaciones clínicopatológicas con genes específicos. Este análisis nos permitió identificar dos asociaciones estadísticamente significativas, metilación de APC y menor sobrevida (Figura 3) y metilación de p16 y p14 en casos de CGD asociado a EBV 22 (Tabla 4).

\section{DisCUSIÓN}

Nuestros resultados muestran una frecuencia importante de metilación de 11 genes en una serie 
Tabla 3. Índice de metilación (IM ) y correlaciones clínico-patológicas en 83 casos de cáncer gástrico difuso

\begin{tabular}{|c|c|c|c|c|c|c|}
\hline & & \multicolumn{2}{|c|}{ IM $<30$} & \multicolumn{2}{|c|}{ IM $>30$} & \multirow[b]{2}{*}{$\mathrm{p}$} \\
\hline & & $\mathrm{N}$ & $\%$ & $\mathrm{~N}$ & $\%$ & \\
\hline \multirow[t]{2}{*}{ Género } & Hombre & 32 & 68 & 21 & 58 & 0,36 \\
\hline & Mujer & 15 & 32 & 15 & 42 & \\
\hline \multirow[t]{2}{*}{ Edad } & $<58$ años & 22 & 47 & 16 & 44 & 0,83 \\
\hline & >58 años & 25 & 53 & 20 & 56 & \\
\hline \multirow[t]{2}{*}{ Sobrevida } & Vivo & 20 & 43 & 15 & 42 & 0,54 \\
\hline & Muerto & 19 & 40 & 19 & 53 & \\
\hline \multirow[t]{2}{*}{ Ubicación } & No antral & 26 & 58 & 22 & 65 & 0,53 \\
\hline & Antral & 19 & 42 & 12 & 35 & \\
\hline \multirow[t]{2}{*}{ Estado } & Incipiente & 7 & 15 & 5 & 14 & 0,87 \\
\hline & Avanzado & 39 & 83 & 31 & 86 & \\
\hline \multirow[t]{2}{*}{ Linfonodos } & Negativo & 10 & 21 & 6 & 17 & 0,49 \\
\hline & Positivo & 29 & 62 & 26 & 72 & \\
\hline \multirow[t]{2}{*}{ Virus Epstein-Barr } & Negativo & 34 & 72 & 22 & 61 & 0,07 \\
\hline & Positivo & 8 & 17 & 13 & 36 & \\
\hline
\end{tabular}

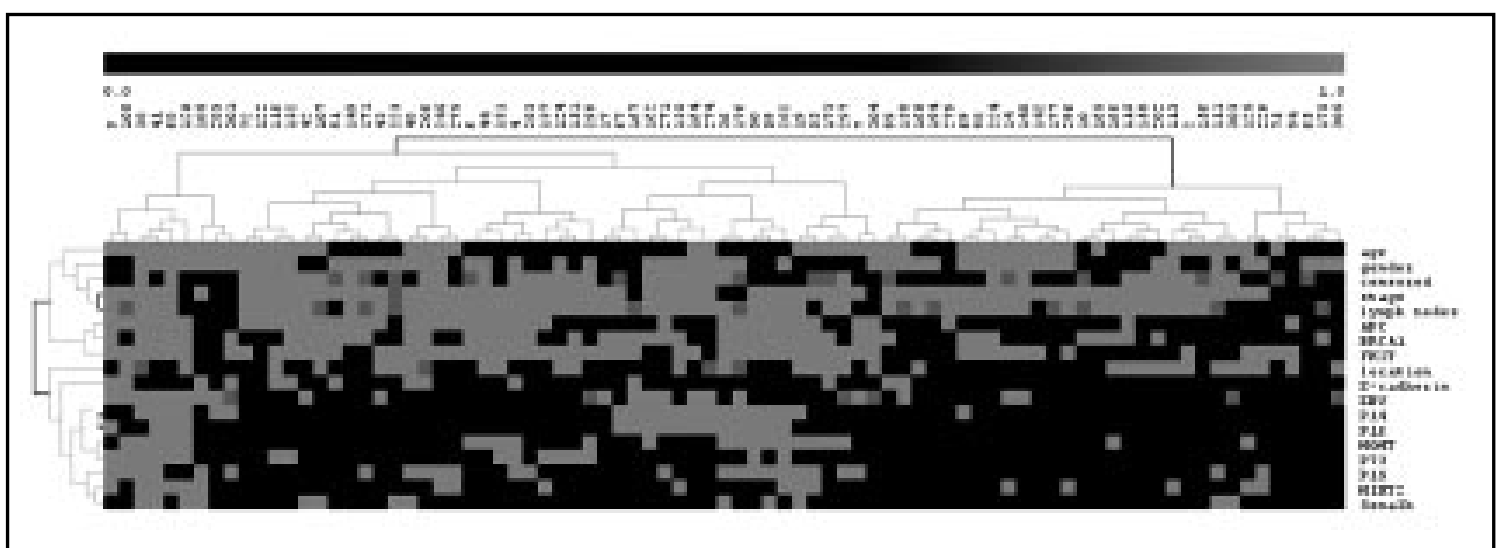

Figura 2. Análisis de hierarchical clustering en 83 casos de cáncer gástrico difuso. Se observan dos clusters, uno superior con todas las variables clínico-patológicas (excepto ubicación y presencia de virus EB) y FHIT, BRCA1 y APC y uno inferior con 8 genes y ubicación e infección por EBV. Se observa una fuerte asociación entre metilación de p16 y p14 e infección por EBV.

consecutiva de CGD. El índice de metilación en nuestros datos confirma el fenotipo metilador en CGD, como ha sido descrito previamente ${ }^{33}$. Sin embargo, el estudio de las correlaciones clínicopatológicas e IM no indica asociaciones significativas que diferencien los grupos alto versus bajo. Sin embargo, el mismo conjunto de datos analizados por hierarchical clustering nos permite una lectura gráfica de asociaciones específicas entre variables clínico-patológicas y genes particulares. Esta estrategia nos permitió la identificación de 3 genes FHIT, BRCA1 y APC, cuya metilación está asociada a variables clínico-patológicas de conocida relevancia en la sobrevida de CGD, como linfonodos y estadio clínico. El análisis estadístico de estas asociaciones nos permitió identificar a la 


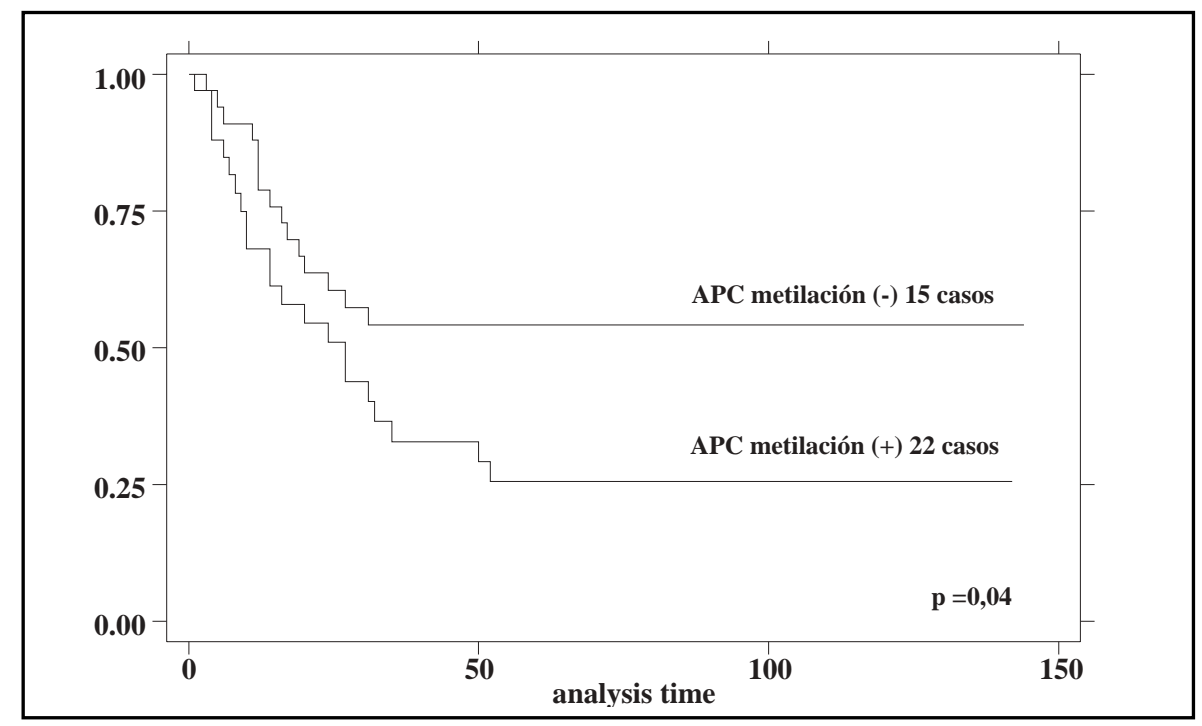

Figura 3. Análisis de sobrevida Kaplan-Meier para comparación de metilación de APC entre carcinomas gástricos difusos.

Tabla 4. Asociaciones del virus de Epstein-Barr y metilación de p14 / p16 en casos de cáncer gástrico difuso

\begin{tabular}{|c|c|c|c|}
\hline & positivo & $\begin{array}{c}\text { EBV } \\
\text { negativo }\end{array}$ & $\mathrm{p}$ \\
\hline \multicolumn{4}{|l|}{ p14 } \\
\hline positivo & 11 & 8 & 0,0006 \\
\hline negativo & 10 & 48 & \\
\hline \multicolumn{4}{|l|}{ p16 } \\
\hline positivo & 10 & 6 & 0,0004 \\
\hline negativo & 11 & 50 & \\
\hline
\end{tabular}

metilación de APC como factor pronóstico en CGD, tal como ha sido descrito recientemente ${ }^{34}$. Sin embargo, no encontramos una asociación entre sobrevida y metilación de FHIT o BRCA1. Esta información no es concordante con la literatura, que señala que la metilación de FHIT está asociada a un estadio tumoral avanzado, alto grado histológico y peor sobrevida ${ }^{35}$. El análisis de hierarchical clustering nos permitió, además, confirmar la asociación entre EBV con metilación de p16 y p14 no sólo en tercio medio, como ha sido descrito previamente ${ }^{36}$, sino a todas las localizaciones del cáncer gástrico. Tomados en conjunto, nuestros datos confirman la potencialidad del análisis de hierarchical clustering para la búsqueda de asociaciones entre variables clínicopatológicas y moleculares en estudios con gran cantidad de biomarcadores. Es interesante la observación que estos mismos resultados no demuestran asociaciones al analizarlos con IM, una aproximación que mide promedios de datos y no datos particulares.

Con respecto a las frecuencias de metilación de los distintos genes en estudio, llama la atención la baja frecuencia relativa de E-caderina, ya que se ha descrito metilada en casi $80 \%$ de casos de CGD $^{29}$. Probablemente, el rendimiento del ensayo MS-PCR para E-caderina está disminuido por el tamaño de la región amplificada (120 pares de bases) y el tipo de muestra utilizada, tejido incluido en parafina ${ }^{37}$. En este sentido, los tres genes que con mayor frecuencia aparecieron como metilados (FHIT, APC y BRCA1), corresponden a tamaños entre 67 y 98 pb. Esta información puede ser relevante al momento de interpretar los resultados, porque pueden estar influidos por el tamaño de la secuencia utilizada para la identificación de genes particulares. Por otra parte, el uso de muestras en tejido 
fijado en formalina, e incluido en parafina, nos permitió el acceso a un número importante de casos de CGD en forma retrospectiva. El contar además en estos casos con información clínicopatológica y de sobrevida, nos permitió generar una información que de otra manera habría tomado años en reunirla en forma prospectiva.

Una proyección de nuestro estudio sería aplicar la metilación de GST en la búsqueda de marcadores de detección precoz en CGD. En este sentido, se ha reportado que los genes APC, cmet, y p53 pueden ser detectados en sueros de pacientes con cáncer gástrico ${ }^{38}$. De nuestro estudio, APC emergería como un potencial candidato para evaluación de tamizaje en pacientes con factores de riesgo o población asintomática. La

\section{REFERENCIAS}

1. Pisani P, Parkin DM, Bray F, Ferlay J. Estimates of the worldwide mortality from 25 cancers in 1990. Int J Cancer 1999; 83: 18-29.

2. Shibuya K, Mathers CD, Boschi-Pinto C, López AD, MURRAY CJ. Global and regional estimates of cancer mortality and incidence by site: II. Results for the global burden of disease 2000. BMC Cancer 2002; 2: 37.

3. Prieto M. Mortalidad por cáncer en Chile. Unidad de Cáncer, Ministerio de Salud, 2000.

4. Serra I, Báez S, Serra J, Calvo A, Decinti E. Evolución epidemiológica reciente del cáncer gástrico en Chile y el mundo. Rev Chil Cir 1997; 49: 54-63.

5. Csendes A, Smok G, Medina E, Salgado I, Rivera R, Quitral M. Caractenísticas evolutivas del cáncer gástrico 1958-1990. Rev Méd Chile 1992; 120: 36-42.

6. BAL M. Risk Factors and Survival in Gastric carcinoma. Departament of Bioestatistics, School of Public Health, Faculty of Medicine, pp. 120. Santiago: Universidad of Chile, 2001.

7. Maruyama K. Surgical treatment and end result of gastric cancer. Gann. Tokyo, 1985.

8. Ohno $\mathrm{S}$, Tomisaki $\mathrm{S}$, Oiwa $\mathrm{H}$, Sakaguchi $\mathrm{Y}$, Ichiyoshi Y, Maehara Y et al. Clinicopathologic characteristics and outcome of adenocarcinoma of the human gastric cardia in comparison with carcinoma of other regions of the stomach. J Am Coll Surg 1995; 180: 577-82.

9. HaNAHAN D, WeinBerg RA. The hallmarks of cancer. Cell 2000; 100: 57-70. aplicación de esta estrategia de prevención secundaria sería un beneficio a la detección precoz del CGD, ya que permitiría focalizar la endoscopia digestiva alta a pacientes con APC metilado en suero. Esta aproximación se encuentra en evaluación en otros tumores, como cáncer colorrectal 39 y cáncer de mama, entre otros.

En resumen, nuestros datos indican que el uso del método de análisis gráfico hierarchical clustering es capaz de identificar asociaciones potencialmente significativas entre variables clínico-patológicas y metilación de GST en una serie consecutiva de CGD, en particular sobrevida y metilación de APC e infección por EBV y metilación de p16 y p14, que mediante otros métodos de asociación estadística no encontramos.

10. Esteleer M, Herman JG. Cancer as an epigenetic disease: DNA methylation and chromatin alterations in human tumours. J Pathol 2002; 196: 1-7.

11. Esteluer M, Fraga MF, Guo M, Garcia-Foncilas J, Hedenfalk I, Godwin A et al. DNA methylation patterns in hereditary human cancers mimic sporadic tumorigenesis. Hum Mol Genet 2001; 10: 3001-7.

12. Tоуота M, Ahuja $\mathrm{N}$, Suzuki $\mathrm{H}$, Iтон F, Оне-Тоуота M, IMAI K ET AL. Aberrant methylation in gastric cancer associated with the $\mathrm{CpG}$ island methylator phenotype. Cancer Res 1999; 59: 5438-42.

13. Tamura G, Yin J, Wang S, Fleisher AS, Zou T, ABRAHAM JM ET AL. E-Cadherin gene promoter hypermethylation in primary human gastric carcinomas. J Natl Cancer Inst 2000; 92: 569-73.

14. Sato S, Yokozaki H, Yasui W, Nikai H, Tahara E. Silencing of the CD44 gene by $\mathrm{CpG}$ methylation in a human gastric carcinoma cell line. Jpn J Cancer Res 1999; 90: 485-9.

15. Sato K, Tamura G, Tsuchiya T, Endoh Y, Usuba O, KimuRA W ET AL. Frequent loss of expression without sequence mutations of the DCC gene in primary gastric cancer. Br J Cancer 2001; 85: 199-203.

16. Lee YY, Kang SH, Seo JY, Jung CW, Lee KU, Choe KJ. Alterations of p16INK4A and p15INK4B genes in gastric carcinomas. Cancer 1997; 80: 1889-96.

17. Kang YH, LeE HS, KIM WH. Promoter methylation and silencing of PTEN in gastric carcinoma. Lab Invest 2002; 82: 285-91.

18. Iida S, Akiyama Y, Nakajima T, IchikaWa W, Nihei $Z$, SUGIHARA K ET AL. Alterations and hypermethyla- 
tion of the p14(ARF) gene in gastric cancer. Int J Cancer 2000; 87: 654-8.

19. Byun DS, Lee MG, Chae KS, Ryu BG, Chi SG. Frequent epigenetic inactivation of RASSF1A by aberrant promoter hypermethylation in human gastric adenocarcinoma. Cancer Res 2001; 61: 7034-8.

20. BevilacQua RA, Simpson AJ. Methylation of the hMLH1 promoter but no hMLH1 mutations in sporadic gastric carcinomas with high-level microsatellite instability. Int J Cancer 2000; 87: 200-3.

21. Hayashi K, Yokozaki H, Goodison S, Oue N, Suzuki $\mathrm{T}$, LotaN R ET AL. Inactivation of retinoic acid receptor beta by promoter $\mathrm{CpG}$ hypermethylation in gastric cancer. Differentiation 2001; 68: 13-21.

22. Yasui W, Oue N, Aung PP, Matsumura S, Shutoh M, NAKAYAMA H. Molecular-pathological prognostic factors of gastric cancer: a review. Gastric Cancer 2005; 8: 86-94.

23. Eisen MB, Spellman PT, Brown PO, Botstein D. Cluster analysis and display of genome-wide expression patterns. Proc Natl Acad Sci USA 1998; 95: 14863-8.

24. LAUREN P. The two histological main types of gastric carcinoma, diffuse and so-called intestinal -type carcinoma. Acta Path Microbiol Scan 1965; 64: 31-49.

25. Corvalán A, Akiba S, Vaienzueia M, Cumsile M, KorIYAma C, ArgandoÑa J et al. Características clínicomoleculares del cáncer gástrico cardial asociado al virus Epstein Barr. Rev Méd Chile 2005; 133: 753-60.

26. Convalán A, Koriyama C, Akiba S, Eizuru Y, BacKhouse C, Palma M et al. Epstein-Barr virus in gastric carcinoma is associated with location in the cardia and with a diffuse histology: a study in one area of Chile. Int J Cancer 2001; 94: 527-30.

27. Herman JG, Graff JR, Myohanen S, Nelkin BD, BAYLN SB. Methylation-specific PCR: a novel PCR assay for methylation status of $\mathrm{CpG}$ islands. Proc Natl Acad Sci USA 1996; 93: 9821-6.

28. Grunau C, Ciark SJ, Rosenthal A. Bisulfite genomic sequencing: systematic investigation of critical expenmental parameters. Nucleic Acids Res 2001; 29: E65-65.

29. TAN LW, Dobrovic A. Methylation analysis of formalin-fixed, paraffin-embedded sections using a nontoxic DNA extraction protocol. Biotechniques 2001; 31: 1354, 1356-7.

30. Kang GH, Lee S, Kim WH, Lee HW, Kim JC, Rhyu
MG ET AL. Epstein-barr virus-positive gastric carcinoma demonstrates frequent aberrant methylation of multiple genes and constitutes $\mathrm{CpG}$ island methylator phenotype-positive gastric carcinoma. Am J Pathol 2002; 160: 787-94.

31. Makarla PB, Saboorian MH, Ashfaq R, Toyooka KO, TоYоoкa S, MinNa JD et al. Promoter hypermethylation profile of ovarian epithelial neoplasms. Clin Cancer Res 2005; 11: 5365-9.

32. Saeed Ai, Sharov V, White J, L J, Lung W, Bhagabati $\mathrm{N}$ ET AL TM4: a free, open-source system for microarray data management and analysis. Biotechniques 2003; 34: 374-8.

33. Leung WK, To KF, Chu ES, Chan MW, Bai AH, Ng EK ET AL. Potential diagnostic and prognostic values of detecting promoter hypermethylation in the serum of patients with gastric cancer. $\mathrm{Br} \mathrm{J}$ Cancer 2005; 92: 2190-4.

34. Bragantini E, Barbi S, Beghem S, Moore PS, dE Manzoni G, Roviewo F et al. Loss of Fhit expression is associated with poorer survival in gastric cancer but is not an independent prognostic marker. J Cancer Res Clin Oncol 2005: 1-6.

35. Vo QN, Geradts J, GuLey ML, Boudreau DA, Bravo JC, SCHNEIDER BG. Epstein-Barr virus in gastric adenocarcinomas: association with ethnicity and CDKN2A promoter methylation. J Clin Pathol 2002; 55: 669-75.

36. Roa JC, Anabalón RL, Roa EI, Tapia EO, Melo A, VILASECA HM ET AL. Estudio del patrón de metilación génico en el cáncer gástrico en Chile. Rev Méd Chile 2005; 133: 874-80.

37. Wang JY, Hsieh JS, Chen CC, Tzou WS, Cheng TL, CHEN FM ET AL. Alterations of APC, c-met, and p53 genes in tumor tissue and serum of patients with gastric cancers. J Surg Res 2004; 120: 242-8.

38. Wang JY, Hsien JS, Chang MY, Huang TJ, Chen FM, Cheng TL et AL. Molecular detection of APC, K-ras, and p53 mutations in the serum of colorectal cancer patients as circulating biomarkers. World J Surg 2004; 28: 721-6.

39. Fiegl H, Miminger S, Mueluer-Holzner E, Marth C, ENSINGer C, Berger A et aL. Circulating tumorspecific DNA: a marker for monitoring efficacy of adjuvant therapy in cancer patients. Cancer Res 2005; 65: 1141-5.

Agradecimientos

Agradecemos la revisión crítica del manuscrito al Dr. Juan Carlos Roa, Universidad de la Frontera, Temuco, Chile. 